\title{
Spatial and behavioural patterns of reef habitat settlement by fish larvae
}

\author{
David Lecchini* \\ Laboratory of Ecology and Systematics, University of the Ryukyus, Senbaru, Nishihara, Okinawa 903-0213, Japan \\ and \\ CRIOBE, Centre de Recherches Insulaires et Observatoire de l'Environnement, Moorea, French Polynesia
}

\begin{abstract}
The transition from a pelagic oceanic environment to a benthic reef environment, during which the relationship between the organism and its environment changes radically, is a particularly dangerous phase of the life cycle of marine organisms. To explore this transition phase in coral reef fish, I worked in Moorea Island lagoon, where oceanic larvae enter the lagoon across the reef crest by night. The fish larvae were captured by night with crest nets, then tagged and released in the lagoon. The day following the night of 'capture-tag-release', I surveyed the lagoon to determine the first benthic habitat of tagged fish. Based on spatial and behavioural components, 4 settlement patterns were highlighted: larvae settled either into the benthic habitat occupied by juveniles of their species (Pattern 1) or into a pre-settlement habitat (Pattern 2) on the first day after reef colonisation, and larvae had either similar behaviour to juveniles (Pattern A), or a cryptic lifestyle (Pattern B). Among the 25 species studied, 13 had settlement Pattern 1A (e.g. Chromis viridis, Acanthurus triostegus), 5 had Pattern 1B (e.g. Lutjanus fulvus, Centropyge flavissimus), 4 had Pattern 2A (e.g. Apogon frenatus, Stegastes nigricans) and 3 had Pattern 2B (e.g. Gymnothorax sp., Scorpaenodes guamensis). Overall, the present study is the first to explore the use of the first larval benthic habitat by a broad range of fish taxa. The most widespread settlement pattern observed (13 out of 25 species) was that which minimises the transition time between pelagic life and life on the reef, namely, larvae going directly to their settlement habitat and immediately acquiring the lifestyle of juveniles.
\end{abstract}

KEY WORDS: Coral reef fish · Marine larvae $\cdot$ Phase of transition · Settlement - Ontogenetic shifts Resale or republication not permitted without written consent of the publisher

\section{INTRODUCTION}

Most marine organisms have life histories with 2 distinct phases: a relatively sedentary benthic phase and a dispersive, mobile pelagic phase (Werner 1988). Individuals must therefore negotiate the hazards of 2 quite different environments during their lifetime, which increases the number of factors that may limit their abundance (Youson 1988). The transition from a pelagic oceanic environment to a benthic reef environment, during which the relationship between the organism and its environment changes radically, is a particularly dangerous phase of their life cycle (Kaufman et al. 1992). Perhaps one of the greatest challenges facing marine reef organisms with pelagic larval stages is, therefore, the need to rapidly be able to meet the demands of life in a lagoon environment.
During this transition, marine larvae that have led a pelagic life for several weeks must adapt without prior experience to benthic life. For coral reef fish, Booth (1991) showed that Dascyllus albisella larvae adapted to juvenile-style benthic life within $24 \mathrm{~h}$. In contrast, Victor (1982) showed that Halichoeres bivittatus larvae spent the first $5 \mathrm{~d}$ after reef colonisation buried in the sand before adopting the lifestyle of the juvenile population. The larvae of marine invertebrates need more time to adapt to the juvenile lifestyle. Larvae of blue crabs Callinectes sapidus spend at least $8 \mathrm{~d}$ in tidal marsh creeks before moving to juvenile habitats (Van Montfrans et al. 1991).

The transition phase is not only perilous for marine larvae, but it is also difficult to study for ecologists, as emphasized by Marliave (1977) and Booth (2002). Little information is available about the ecological 
phase bridging late oceanic larval and early benthic juvenile stages for fish and marine invertebrates (e.g. Breitburg 1991, Van Montfrans et al. 1991, Kaufman et al. 1992, Booth 2002). This lack of information may be due to the larvae being generally cryptic (larvae hidden in coral colonies, macro-algae, sand, etc.) and settling at night (Booth 1991, Dufour \& Galzin 1993).

The present study on spatial and behavioural patterns of settlement by coral reef fish larvae on the north coast of Moorea Island (French Polynesia) was designed to answer 2 questions: (1) How long does it take a larva to settle into the benthic habitat of juveniles once it enters the lagoon? (2) Does the larva immediately adopt the juvenile lifestyle of its species?

\section{MATERIALS AND METHODS}

Study area. The present study was conducted on the north coast of Moorea lagoon (Matautia sector: $17^{\circ} 30^{\prime} \mathrm{S}, 149^{\circ} 5^{\prime} \mathrm{W}$ ). This location was divided into 14 distinct reef zones (Rz) based on depth, wave exposure and substratum composition (Fig. 1). In previous studies, I identified the juvenile benthic habitat for over 100 diurnal and nocturnal fish species on the Matautia sector (see Lecchini 2003, Lecchini \& Galzin 2005).

Sampling protocol. Larvae were captured at night with crest nets when they entered the lagoon and were tagged. Subcutaneous injections (Panfili 1992) and batch tagging (Pavlov \& Grin 1984) were chosen as tagging techniques because they work on larvae (small, fragile individuals) and can be applied in situ (tagging was performed on a boat moored on the reef crest).

Several vital stains (by batch tagging: methylene blue, Bismark brown, eosine, neutral red, methyl green; by injection: alcian blue, indigo carmin, orange G) were assessed at different concentrations and batch durations to determine which was the most visible and caused the lowest mortality after $24 \mathrm{~h}$. A total of 1356 tagged larvae from 30 species were monitored in aquaria from May to June 2001 (raw data in Lecchini 2003). Bismark brown and neutral red were found to be the most effective for batch tagging (batch duration $1 \mathrm{~h}$; concentration varied by species), while alcian blue $\left(1.25 \mathrm{~g} \mathrm{l}^{-1}\right)$ and orange $\mathrm{G}\left(5 \mathrm{~g} \mathrm{l}^{-1}\right)$ were found to be the most effective for injections.

Every Sunday, Tuesday and Thursday during July, August and December 2001, and January 2002, the author spent from 19:00 to 03:30 h on the reef crest of Matautia sector using 3 crest nets $(4 \mathrm{~m}$ of linear net opening for capture) to capture larvae. The nets were emptied every $2 \mathrm{~h}(21: 00,23: 00$ and 01:00 h) using a boat anchored behind the reef crest. The captured larvae were sorted by species and tagged. The tagged larvae were kept for $1 \mathrm{~h}$ in a cage immersed alongside the boat before being released on the reef crest. They were released by 03:30 $\mathrm{h}$ to give them time to choose a benthic habitat before sunrise (at about 05:30 h).

The author searched for tagged larvae on the days following the night of capture (i.e. on Monday,

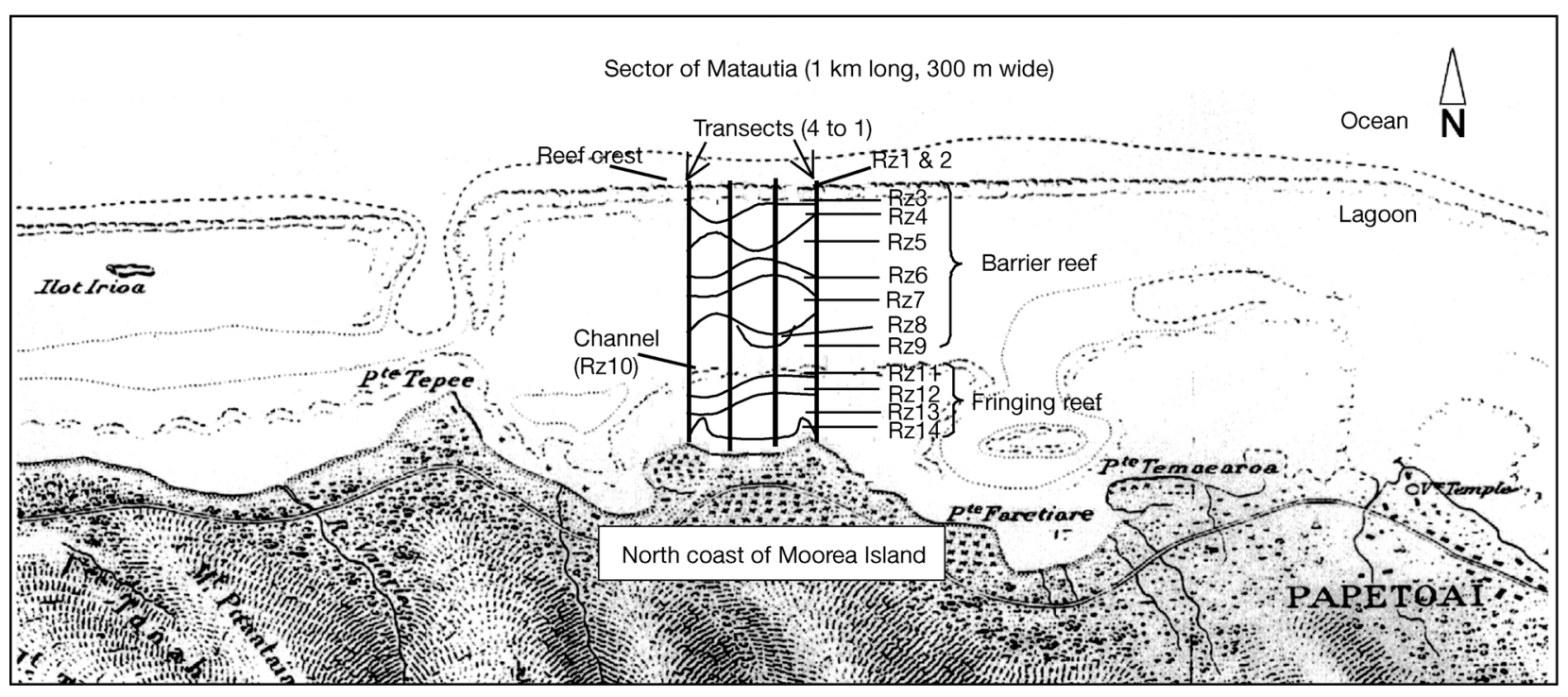

Fig. 1. Schematic view of reef zones (Rz) and transects (bands $1 \mathrm{~km}$ long and $1 \mathrm{~m}$ wide, continuous from coast to reef crest) sampled on the north coast of Moorea Island (Matautia sector). Rz1: small channel (reef zone made up of only coral rubble and depth

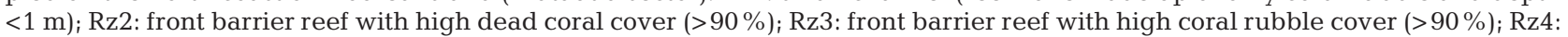
mid-barrier reef with high living coral cover (>30\%); Rz5: mid-barrier reef with low living coral cover (<30\%); Rz6: deep-barrier reef (low-living coral cover and depth $>2 \mathrm{~m}$ ); Rz7: dead coral zone ( $>80 \%$ of corals are dead); Rz8: huge Porites rus colony (31 m wide, 80 m long, 2 m high); Rz9: deep lagoonal slope on barrier reef; Rz10: channel; Rz11: deep lagoonal slope on fringing reef; Rz12: mid-fringing reef with high living coral cover (>30\%); Rz13: micro-atoll area; Rz14: sand zone 
Wednesday and Friday) using the ichthyocide rotenone and diurnal and nocturnal visual surveys. The visual surveys involved a meticulous search of Transects 2, 3 and 4 (Fig. 1), then quick searching between transects ( 5 to $6 \mathrm{~h}$ of diurnal visual surveys and 3 to $4 \mathrm{~h}$ of nocturnal visual surveys). When a tagged larva was found, the author recorded (1) the habitat on which it was found, (2) whether the larva manifested juvenile behaviour and (3) the number of non-tagged larvae of the same species and size on the same habitat. The latter were presumed to have colonised at the same time as the tagged larva. For rotenone capture, 6 coral patches were chosen each day at random between Transects 1 and 2 to search for tagged larvae (especially those of species with a cryptic lifestyle).

The habitat on which each tagged larva was found was classified at both macro- (by reef zone) and microscales (by shelter category). Shelter categories were sand, coral rubble, coral slab, algae (distinguishing macro-algae, encrusting calcareous algae, and turf) and coral (distinguishing coral form, genus and state [dead or alive]).

The sampling protocol distinguished 4 settlement patterns (1A, 1B, 2A and 2B) based on spatial and behavioural components. The spatial component was whether larvae settled into the benthic habitat occupied by juveniles (Pattern 1) or into a pre-settlement habitat (Pattern 2) on the first day after reef colonisation. To define the behavioural component (Pattern A or B), the position and social interactions of tagged larvae were recorded, i.e. whether each larva was swimming outside its shelter or hiding in the coral cracks, and whether each larva was swimming alone or with conspecifics or was being chased by conspecifics. These data allowed the author to determine whether the larva had adopted the juvenile lifestyle of its species (Pattern A) or a different lifestyle (Pattern B).

\section{RESULTS}

A total of 2027 larvae from 25 species were tagged and $11.3 \%$ of all tagged larvae were later found in the lagoon (Table 1). For example, 212 Acanthurus triostegus larvae were captured and tagged during the 4 sampling months and $38(17.9 \%)$ were found in the lagoon on the first day after reef colonisation. Moreover, 106 untagged $A$. triostegus larvae of the same size and with similar morphological characters were found on the habitat of tagged larvae. All these larvae were found in holes of coral slab with some macroalgae in reef zone 14 (Rz14, see Fig. 1), the benthic habitat of A. triostegus juveniles (Lecchini 2003, Lecchini \& Galzin 2005). Therefore, A. triostegus larvae settled directly into the juvenile habitat (Pattern 1). As larvae swam above the substrate with other A. triostegus juveniles and showed the same behaviour, the settlement pattern was $1 \mathrm{~A}$.

Among the 25 species recorded, 13 had settlement Pattern 1A, 5 had Pattern 1B, 4 had Pattern 2A and 3 had Pattern 2B (Table 1). Although the benthic habitats of juveniles differed among species in the same family, the species all had the same settlement pattern, except for Pomacentridae; Stegastes nigricans exhibited the 2 spatial components (Patterns 1 and 2). Furthermore, all larvae not behaving like the juveniles of their species (Pattern B) adopted a cryptic lifestyle (living alone and hiding in the coral cracks, rubble or coral colonies). For example, Lutjanus fulvus larvae spent several days hiding in living coral colonies of Porites sp. before joining the juvenile population.

For one species (Stegastes nigricans), the abundance of a larval cohort could be followed over the period of 1 mo by regular visual surveys on Transect 3 (Monday, Wednesday and Friday of each week in July; Fig. 2). During this month, all S. nigricans larvae (tagged and untagged) coming from 3 successive high-colonisation peaks (colonisation size: $18.2 \mathrm{~mm} \pm 0.4 \mathrm{SE}, \mathrm{n}=30$ ) were found in pre-settlement habitat (coral rubble found in Rz1 and 2). S. nigricans individuals were categorised into 3 size classes. The first size class (15 to $20 \mathrm{~mm}$ ) was never observed on settlement habitat (branched masses of Porites with algal turf, found between Rz3 and 9), indicating Pattern 2. The second size class (20 to $25 \mathrm{~mm}$ ) was present on both pre-settlement and settlement habitats, and the 25 to $30 \mathrm{~mm}$ size class was only present on settlement habitat. Therefore, $S$. nigricans had a pre-settlement phase of variable duration but always migrated to settlement habitat (possibly associated with a differential mortality) by the time it grew to $25 \mathrm{~mm}$.

\section{DISCUSSION}

To describe the transition phase of coral reef fish at Moorea Island, 4 settlement patterns were identified for 25 species, with Pattern 1 prevailing (directly settling into the benthic habitat of juveniles) over Pattern 2 (existence of pre-settlement habitat), and Pattern A (behaviour of larvae similar to juveniles) prevailing over Pattern B (behaviour of larvae different to that of juveniles, characterised by a cryptic lifestyle). These 4 settlement patterns highlight that larvae of different species can adopt a different set of settlement 'sequences' to acquire suitable space in the reef environment.

The most widespread settlement pattern observed (13 out of 25 species) was that which minimises the transition time between pelagic life and life on the reef, i.e. larvae going directly to their settlement habi- 
Table 1. Spatial and behavioural patterns of benthic juvenile reef habitat by fish larvae. Number of larvae tagged, and of tagged and associated untagged larvae found in the lagoon. The habitat on which tagged larvae were found and the juvenile habitat are specified by reef zone (Rz) number (see Fig. 1)

\begin{tabular}{|c|c|c|c|c|c|c|c|c|c|}
\hline \multirow[t]{2}{*}{ Species } & \multicolumn{2}{|c|}{ Larvae tagged } & \multicolumn{2}{|c|}{$\begin{array}{c}\text { Tagged larvae } \\
\text { encountered }\end{array}$} & \multicolumn{2}{|c|}{$\begin{array}{c}\text { Untagged larvae } \\
\text { encountered }\end{array}$} & \multirow[t]{2}{*}{$\begin{array}{l}\text { First habitat } \\
\text { of larvae }\end{array}$} & \multirow[t]{2}{*}{$\begin{array}{l}\text { Juvenile } \\
\text { habitat }\end{array}$} & \multirow[t]{2}{*}{$\begin{array}{c}\text { Settlement } \\
\text { pattern }\end{array}$} \\
\hline & Jul-Aug & Dec-Jan & Jul-Aug & Dec-Jan & Jul-Aug & Dec-Jan & & & \\
\hline \multicolumn{10}{|l|}{ Muraenidae } \\
\hline Gymnothorax sp. & 91 & 13 & 3 & 0 & 0 & 0 & Rz2 & Rz4 to 12 & $2 \mathrm{~B}$ \\
\hline \multicolumn{10}{|l|}{ Holocentridae } \\
\hline Myripristis adusta & 3 & 0 & 1 & 0 & 15 & 0 & Rz6 & Rz1 to 14 & $1 \mathrm{~A}$ \\
\hline Myripristi pralinia & 61 & 22 & 13 & 4 & 11 & 6 & Rz6 & Rz1 to 14 & $1 \mathrm{~A}$ \\
\hline Neoniphon sammara & 3 & 8 & 0 & 1 & 0 & 0 & Rz12 & Rz11 to 14 & $1 \mathrm{~A}$ \\
\hline \multicolumn{10}{|l|}{ Scorpaenidae } \\
\hline Scorpaenodes guamensis & 2 & 1 & 1 & 0 & 0 & 0 & Rz2 & Rz3 to 7 & $2 \mathrm{~B}$ \\
\hline Scorpaenodes parvipinnis & 12 & 1 & 2 & 0 & 0 & 0 & Rz2 & Rz3 to 7 & 2B \\
\hline \multicolumn{10}{|l|}{ Apogonidae } \\
\hline Apogon exostigma & 121 & 11 & 4 & 0 & 13 & 0 & Rz1 & Rz6 to 13 & $2 \mathrm{~A}$ \\
\hline Apogon frenatus & 6 & 2 & 1 & 0 & 4 & 0 & Rz1 & Rz4 to 9 & $2 \mathrm{~A}$ \\
\hline Apogon novemfasciatus & 10 & 10 & 0 & 2 & 0 & 6 & Rz1 & Rz3 to 7 & $2 \mathrm{~A}$ \\
\hline \multicolumn{10}{|l|}{ Mugilidae } \\
\hline Crenimugil crenilabis & 0 & 4 & 0 & 2 & 0 & 14 & Rz14 & Rz12 to 14 & $1 \mathrm{~A}$ \\
\hline \multicolumn{10}{|l|}{ Lutjanidae } \\
\hline Lutjanus fulviflamma & 0 & 56 & 0 & 10 & 0 & 0 & Rz13 & Rz12 to 14 & 1B \\
\hline Lutjanus fulvus & 0 & 93 & 0 & 17 & 0 & 220 & Rz13 & Rz12 to 14 & 1B \\
\hline \multicolumn{10}{|l|}{ Pomacanthidae } \\
\hline Centropyge flavissimus & 19 & 13 & 3 & 3 & 4 & 0 & Rz3 & Rz3 & 1B \\
\hline \multicolumn{10}{|l|}{ Mullidae } \\
\hline Mulloides flavolineatus & 105 & 120 & 18 & 6 & 33 & 2 & Rz14 & Rz14 & $1 \mathrm{~A}$ \\
\hline \multicolumn{10}{|l|}{ Pomacentridae } \\
\hline Chromis viridis & 31 & 249 & 1 & 15 & 7 & 61 & Rz12 \& 13 & Rz12 \& 13 & $1 \mathrm{~A}$ \\
\hline Chrysiptera leucopoma & 102 & 14 & 4 & 2 & 12 & 2 & Rz3 & Rz3 to 5 & $1 \mathrm{~A}$ \\
\hline Stegastes albifasciatus & 55 & 18 & 7 & 0 & 16 & 0 & Rz13 & Rz9 to 13 & $1 \mathrm{~A}$ \\
\hline Stegastes nigricans & 195 & 116 & 10 & 2 & 30 & 16 & Rz1 \& 2 & Rz3 to 9 & $2 \mathrm{~A}$ \\
\hline Stegastes nigricans & Same & Same & 1 & 0 & 0 & 0 & Rz4 & & $1 \mathrm{~A}$ \\
\hline \multicolumn{10}{|l|}{ Labridae } \\
\hline Thalassoma amblycephalum & 0 & 36 & 0 & 8 & 0 & 29 & Rz3 & Rz3 to 5 & $1 \mathrm{~A}$ \\
\hline \multicolumn{10}{|l|}{ Acanthuridae } \\
\hline Acanthurus nigricauda & 0 & 88 & 0 & 15 & 0 & 21 & Rz13 & Rz11 to 14 & $1 \mathrm{~A}$ \\
\hline Acanthurus triostegus & 139 & 73 & 28 & 10 & 89 & 17 & Rz14 & Rz14 & $1 \mathrm{~A}$ \\
\hline Ctenochaetus striatus & 136 & 9 & 22 & 0 & 21 & 0 & Rz4 \& 8 & Rz1 to 14 & $1 \mathrm{~A}$ \\
\hline \multicolumn{10}{|l|}{ Balistidae } \\
\hline Rhinecanthus aculeatus & 0 & 35 & 0 & 8 & 0 & 35 & Rz14 & Rz14 & $1 \mathrm{~A}$ \\
\hline \multicolumn{10}{|l|}{ Tetraodontidae } \\
\hline Canthigaster bennitti & 20 & 0 & 1 & 0 & 0 & 0 & Rz4 & Rz3 to 7 & 1B \\
\hline Canthigaster janthinoptera & 10 & 0 & 1 & 0 & 0 & 0 & Rz5 & Rz3 to 7 & $1 \mathrm{~B}$ \\
\hline Total & 2027 & 229 & 492 & & & & & & \\
\hline
\end{tabular}

tat and immediately acquiring the lifestyle of juveniles (Pattern 1A). For other organisms such as insects or amphibians, the transition phase is also characterised by abrupt and marked ontogenetic changes in habitat use, morphology, physiology and behaviour (Youson 1988). Shortening the transition period may limit larval exposure to predation in a habitat different from the juvenile habitat. Behaviour consistent with avoiding predation during the transition phase has been previously reported among settling fish larvae (Leis 1991), and the settlement patterns used by larvae may be such a response. Indeed, larvae require refuge and food for their survival and growth. It may be hard for a naïve larva to assess these resources at a site directly, especially with regard to their availability over time. The presence of juvenile conspecifics could be an indicator of habitat quality to the settling larvae and if resources are not limited, growth and survival may be enhanced by settling among conspecifics (Ohman et al. 1998).

If settlement Pattern $1 \mathrm{~A}$ is the best, why do some species use Patterns 2 (pre-settlement habitat) and/or 

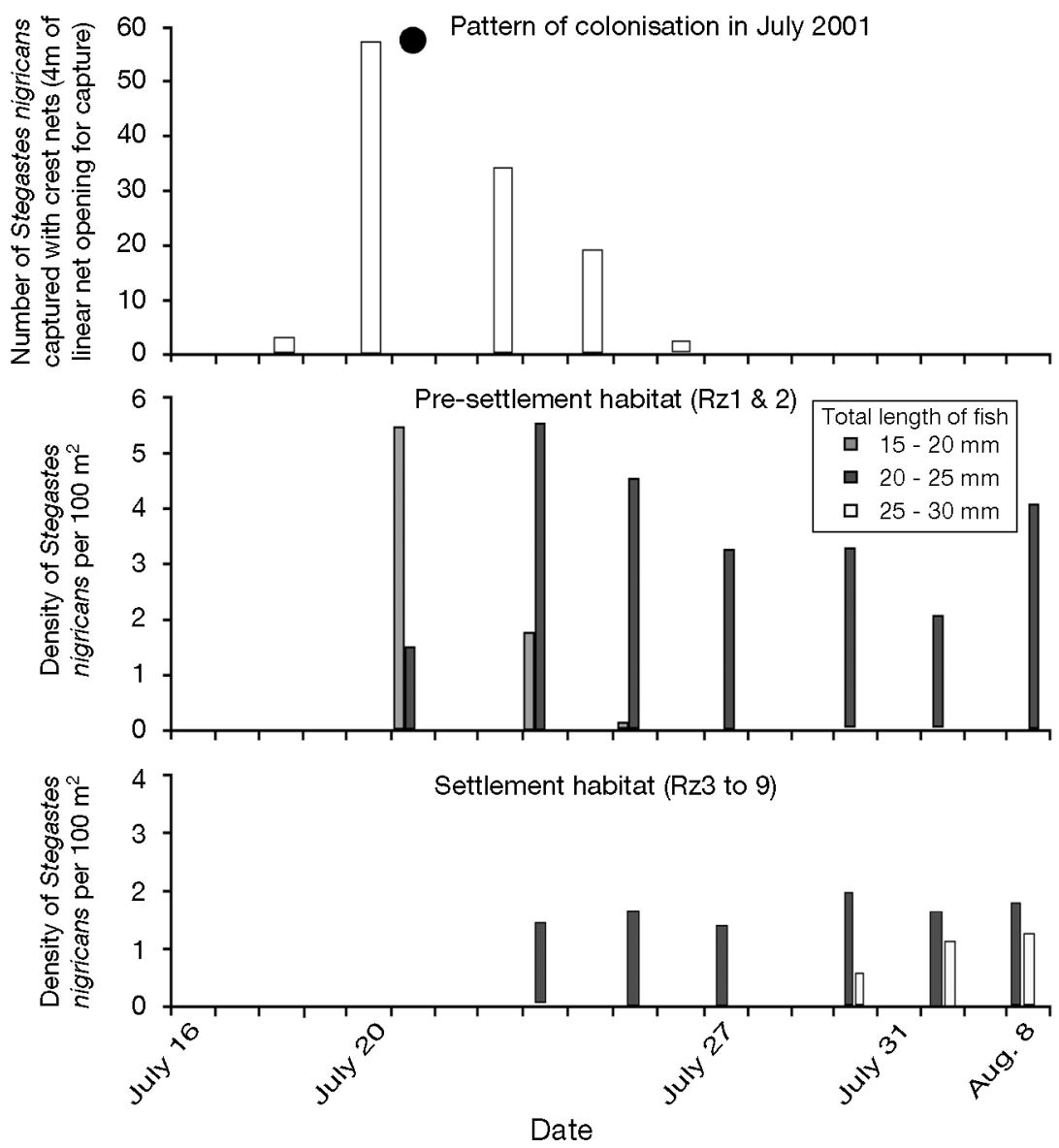

Fig. 2. Stegastes nigricans. Colonisation pattern and larval cohort abundance of $S$. nigricans on their pre-settlement and settlement habitats from the last to the first quarter moon in July 2001. 0: new moon (20 July). See Fig. 1 for description of reef zones (Rz)

that were the most stressed by the manipulations (capture-tag-release).

Overall, direct observations of marine larvae settling naturally on the reef are difficult to obtain. Patterns of habitat selection by larvae are typically inferred from censuses some days after settlement, but this does not make it possible to distinguish between the effects of habitat selectivity by larvae, mortality immediately following settlement, and post-settlement relocation by experienced juveniles (see Vigliola \& Harmelin-Vivien 2001). The present study is the first to explore the use of first larval benthic habitat by a broad range of fish taxa. Similar studies are now required to establish the spatio-temporal generality of the 4 settlement patterns and to document the determinism of spatial and behavioural components used by marine larvae.

Acknowledgements. The author wishes to thank J. Algret, Y. Chancerelle and J. O. Irisson for their assistance in the field and Dr. P. Kretchmer (kretchmer@sfedit.net) at San Francisco Edit for his assistance in editing this manuscript. This research was supported by a Lavoisier Fellowship (French Ministry to Foreign Affairs) awarded to D.L.

\section{LITERATURE CITED}

B (cryptic lifestyle)? McCormick et al. (2002) studied the metamorphosis of many coral-reef fish species. Combining their data with those of this study reveals that if a species has a long metamorphosis period, it is more likely that its larvae linger in a pre-settlement habitat (Pattern 2). Thus, all Pomacentridae species studied by McCormick et al. (2002) have metamorphosis periods of $<72 \mathrm{~h}$, except for Stegastes nigricans $(168 \mathrm{~h})$, which is the only Pomacentridae species to use Pattern 2. Similarly, Apogonidae and Scorpaenidae species have the longest metamorphosis periods (285 h), and all use Pattern 2. It makes sense that slow metamorphosis would be correlated with the use of a pre-settlement habitat and also with a cryptic lifestyle, because larval morphology, physiology and diet are not yet adapted to a lagoon environment. Moreover, a cryptic lifestyle might reduce intra-specific (for Pattern 1B) and interspecific (for Pattern 2B) interactions between larvae and juveniles (Kaufman et al. 1992). Lastly, the species using Patterns 2 and/or B might have been those
Booth DJ (1991) The effects of sampling frequency on estimates of recruitment of the domino damselfish Dascyllus albisella (Gill). J Exp Mar Biol Ecol 145:149-159

Booth DJ (2002) Distribution changes after settlement in six species of damselfish (Pomacentridae) in One Tree Island lagoon, Great Barrier Reef. Mar Ecol Prog Ser 226: 157-164

Breitburg DL (1991) Settlement patterns and presettlement behavior of the naked goby, Gobiosoma bosci, a temperate oyster reef fish. Mar Biol 109:213-221

Dufour V, Galzin R (1993) Colonisation patterns of reef fish larvae to the lagoon at Moorea Island, French Polynesia. Mar Ecol Prog Ser 102:143-152

Kaufman L, Ebersole J, Beets J, McIvor CC (1992) A key phase in the recruitment dynamics of coral reef fishes: post-settlement transition. Environ Biol Fish 34:109-118

Lecchini D (2003) Identification of habitat use strategies between the colonisation and recruitment stages of coral reef fish in the lagoon of Moorea (French Polynesia): approach by behavioural ecology. PhD thesis, University of Paris VI

Lecchini D, Galzin R (2005) Spatial repartition and ontogenetic shifts in habitat use by coral reef fishes (Moorea, French Polynesia). Mar Biol 147:47-58 
Leis JM (1991) The pelagic stage of reef fishes. In: Sale PF (ed) The ecology of fishes on coral reefs. Academic Press, San Diego, CA, p 183-230

Marliave JB (1977) Substratum preferences of settling larvae of marine fishes reared in the laboratory. J Exp Mar Biol Ecol 27:47-60

McCormick MI, Makey LJ, Dufour V (2002) Comparative study of metamorphosis in tropical reef fishes. Mar Biol 141:841-853

Ohman MC, Munday PL, Jones GP, Caley MJ (1998) Settlement strategies and distribution patterns of coral-reef fishes. J Exp Mar Biol Ecol 225:219-238

Panfili J (1992) Estimation de l'âge individuel des poissons: méthodologies et applications à des populations naturelles tropicales et tempérées. PhD thesis, University of Montpellier

Pavlov DS, Grin AN (1984) Use of rheotactic movement

Editorial responsibility: Charles Birkeland (Contributing

Editor), Honolulu, Hawaii, USA indices to assess suitability of vital stains as tag for juvenile fish. J Ichthyol 34:163-166

Van Montfrans J, Ryer CH, Orth RJ (1991) Population dynamics of blue crab Callinectes sapidus in a lower Chesapeake Bay tidal marsh creek. J Exp Mar Biol Ecol 153:1-14

Victor BC (1982) Daily otolith increments and recruitment in two coral reef grasses, Thalassoma bifasciatum and Halichoeres bivittatus. Mar Biol 71:203-208

Vigliola L, Harmelin-Vivien M (2001) Postsettlement ontogeny in three mediterranean reef fish species of the genus Diplodus. Bull Mar Sci 68:271-286

Werner EE (1988) Size, scaling and the evolution of complex life cycles. In: Ebenman B, Perssons L (eds) Size-structured populations. Springer-Verlag, Berlin, p 61-81

Youson JH (1988) First metamorphosis. In: Hoar WS, Randall DJ (eds) Fish physiology. Academic Press, London, p 135-196

Submitted: July 6, 2004; Accepted: April 15, 2005

Proofs received from author(s): September 20, 2005 